\title{
Steroids in Maxillofacial Space Infection: A Retrospective Cohort Study
}

\author{
Li Fong Low, Harshinie Audimulam, Hui Woon Lim, Kalpana Selvaraju, Sathesh Balasundram \\ Department of Oral and Maxillofacial Surgery, Hospital Sultanah Nora Ismail Batu Pahat, Johor, Malaysia \\ Email: lowlifong@gmail.com
}

How to cite this paper: Low, L.F., Audimulam, H., Lim, H.W., Selvaraju, K. and Balasundram, S. (2017) Steroids in Maxillofacial Space Infection: A Retrospective Cohort Study. Open Journal of Stomatology, 7, 397-407.

https://doi.org/10.4236/ojst.2017.79034

Received: June 8, 2017

Accepted: September 5, 2017

Published: September 8, 2017

Copyright $\odot 2017$ by authors and Scientific Research Publishing Inc. This work is licensed under the Creative Commons Attribution International License (CC BY 4.0).

http://creativecommons.org/licenses/by/4.0/

\begin{abstract}
Maxillofacial space infection (MSI) is one of the most common conditions encountered in oral and maxillofacial surgery clinics. Early recognition and proper management of MSI could prevent a life-threatening event. Objectives: To report a series of MSI managed with antibiotics, surgical intervention and exogenous steroids as an adjunct, highlighting functional improvement following steroid administration. Methods: A retrospective cohort study was carried out from December 2013 to September 2016, involving 30 patients ( $\mathrm{n}=30,22$ males, 8 females) diagnosed with MSI. All patients were initially managed with intravenous empirical antibiotics, analgesics and removal of potential source of infection. A course of 3 doses of IV Dexamethasone $8 \mathrm{mg}$ at an interval of 8 hours was started during the first day of hospital admission. Results: This series reports 30 patients presenting with MSI, who received prompt antibiotics and 3 doses of steroids as in-patients. Significant clinical improvement was noted in the form of amelioration of pain, rapid reduction in edema, and improved trismus, shortening hospital stay to an average of 3.5 days, and omission of surgical intervention in $50 \%$ of our cases. No adverse effects or drug reaction was noted. Conclusion: In conclusion, the value of synergistic use of corticosteroids with antibiotics in management of MSI is significant. Despite these promising findings, there is scarce evidence in the literature to fully support the use of corticosteroids in abscess management. The role of corticosteroids in treatment of MSI should be explored further.
\end{abstract}

\section{Keywords}

Maxillofacial Space Infections, Abscess, Odontogenic Infections, Systemic Steroids, Adjunctive Management

\section{Introduction}

Maxillofacial space infection (MSI) refers to infection in the potential spaces and 
fascial planes of the maxillofacial region, a region with a complex anatomy [1]. MSI accounts for one of most common dental-related attendances at emergency departments. The main etiologies of MSI are odontogenic infection, lymphadenitis, and trauma [2], with odontogenic infection accounting as a major contributor. A nationwide Emergency Department survey of 450 hospitals in 27 US states in 2007 showed 302,507 visits attributed to facial cellulitis from dental origin [3]. Severe odontogenic infection remains an important public health concern and has become a significant economic burden to public health care facilities. A retrospective study done by Jundt JS et al (2012) on 42 patient records of inpatients treated for odontogenic infections reported a cost of $\$ 749,382$ averaging $\$ 17,842$ per person [4]. Another nationwide inpatient sample taken in 2008 from 1056 hospitals in 42 US states shows 4044 hospital discharges with a primary diagnosis of mouth abscess/cellulitis, accounting for $\$ 98$ million of hospitalization charges at a mean hospital charge of $\$ 24,240$ per patient [5].

MSI carries significant risk of morbidities and mortality. Late, incorrect or non-treatment could lead to life-threatening complications, such as airway compromise [1] [2] [4] [6]-[13], descending necrotizing mediastinitis [1] [2] [6]-[18], Lemierre syndrome [7] [11] [12], carotid artery erosion and rupture [7], pericarditis [7], brain abscess [19] [20] [21] [22], cavernous sinus thrombosis [23] [24], meningitis [25], thoracic and abdomino-perineal extension of abscess [26], necrotizing fasciitis [13] and sepsis [1] [2] [4] [6] [7] [10] [13] [15]. In the pre-antibiotic era, odontogenic infections were associated with a mortality rate of $10 \%-40 \%$ [27]. The advent and implementation of modern antibiotics have significantly reduced mortality rates associated with odontogenic infections [4].

Treatment of MSI involves early recognition and correct diagnosis, prompt initiation of antibiotic therapy, removal of potential source of infection with or without surgical intervention.

Usual clinical presentations of MSI include swelling, trismus, pain, odynophagia, and dysphagia, which are partly attributed to inflammatory component that accompanies infection. This inflammatory response is sometimes responsible for an exaggerated clinical presentation. Corticosteroids have been used to treat edema and inflammation in various head and neck diseases [28]. We therefore postulated that corticosteroids may also have a beneficial role in the management of MSI. The present study offers a retrospective cohort analysis of MSI patients treated in Department of Oral and Maxillofacial Surgery, Hospital Sultanah Nora Ismail (Batu Pahat, Johor, Malaysia) managed with antibiotics, surgical intervention and exogenous steroids as an adjunct, highlighting functional improvement following steroid administration.

\section{Materials and Methods}

A retrospective cohort study was done, involving the consecutive inclusion of patients with MSI treated in our unit (Oral and Maxillofacial Surgery Unit, Hospital Sultanah Nora Ismail, Batu Pahat, Malaysia) from December 2013 to Sep- 
tember 2016. The study sample involves 30 patients.

\section{Inclusion criteria:}

1) Patients with maxillofacial space infection requiring hospital admission. Criteria for hospital admission include: Trismus, fever, dysphagia, odynophagia, dyspnoea and/or worsening general condition

2) Patients who complied to required stay in ward

\section{Exclusion criteria:}

1) Patients who were diabetic, anaemic, or with history of possible gastrointestinal ulcerative disease

2) Patients who were not compliant to required stay in ward

3) Patients with compromised host defences

a) Patients who are on immunosuppressive/cytotoxic therapy

b) Patients with diseases that compromise their immunity (e.g. AIDS, Leukemia etc.)

The basic diagnostic protocol included anamnesis, examination of oral cavity/ infection site and the use of imaging techniques (intraoral periapical radiographs, occlusal radiographs, or orthopantomogram) to achieve the diagnosis. Laboratory tests were also requested: full blood count for all cases, and other tests according to case based needs.

Management protocol was based on intravenous antibiotic treatment along with adjunctive steroids, with or without surgical intervention. All patients were initially managed with intravenous empirical antibiotics (IV Augmentin $1.2 \mathrm{gm}$ TDS or IV Unasyn 1.5 gm TDS), analgesics (Tab Ibuprofen 400mg or IM Voltaren $400 \mathrm{mg}$ or IM Tramal $50 \mathrm{mg}$ TDS) and removal of potential source of infection. A course of 3 doses of IV Dexamethasone $8 \mathrm{mg}$ at an interval of 8 hours was started during the first day of hospital admission after obtaining a full blood count with parameters within normal range. Surgical intervention was considered in cases requiring drainage of underlying collection, and in some cases a drain was placed in situ for several days to enable continued drainage.

Demographic data collected were patient age, gender, ethnicity, and parameters relating to medical history. Specific outcomes were measured: number of anatomic spaces involved, changes in mouth opening and swelling size, length of hospital stay and need for surgical intervention. All MSI patients treated in this unit, from December 2013 to September 2016, are identified from patient registry following inclusion criteria and exclusion criteria stated. Patients' clinical records are then reviewed and demographic data and specific outcomes are recorded in data collection form. All data and information collected were tabulated and arranged electronically (Microsoft Excel spreadsheet) and analysed descriptively.

\section{Results}

A total of 30 patients were reviewed based on the inclusion criteria, 22 of which male and 8 female. Only 2 pediatric patients, ages 6 and 7 years old, were treated. 
The mean age of the group was 32.1 years [Table 1]. Mandible (67\%) was more frequently involved than maxilla (33\%) [Figure 1]. Involvement of the left side $(50 \%)$ was slightly more than right $(40 \%)$, whereas $1 \%$ of infections were

Table 1. Demographic data of patients.

\begin{tabular}{|c|c|c|c|c|c|c|c|}
\hline Case & Age & Sex & $\begin{array}{l}\text { Anatomic } \\
\text { space }\end{array}$ & $\begin{array}{c}\text { LOS } \\
\text { (days) }\end{array}$ & $\begin{array}{c}\text { Surgical } \\
\text { intervention } \\
\text { (I \& D) }\end{array}$ & $\begin{array}{l}\text { Change in } \\
\text { swelling } \\
\text { size }(\mathrm{cm})\end{array}$ & $\begin{array}{c}\text { Change in } \\
\text { mouth } \\
\text { opening }(\mathrm{cm})\end{array}$ \\
\hline 1 & 30 & $\mathrm{M}$ & $\mathrm{SM}$ & 4 & $\sqrt{ }$ & 3 & 1 \\
\hline 2 & 17 & $\mathrm{M}$ & SMen & 3 & $x$ & 3 & 1.5 \\
\hline 3 & 33 & $\mathrm{M}$ & B & 4 & $\sqrt{ }$ & 2.5 & 0.5 \\
\hline 4 & 22 & $\mathrm{M}$ & B & 3 & $x$ & 2 & -1 \\
\hline 5 & 52 & $\mathrm{~F}$ & $\mathrm{C}$ & 3 & $\sqrt{ }$ & 2 & 0 \\
\hline 6 & 28 & $\mathrm{M}$ & B & 3 & $\sqrt{ }$ & 3 & -2.5 \\
\hline 7 & 29 & $\mathrm{M}$ & SMass & 4 & $\sqrt{ }$ & 3.5 & -1 \\
\hline 8 & 20 & $\mathrm{M}$ & $\mathrm{B}, \mathrm{SM}$ & 3 & $\sqrt{ }$ & 4 & 0.5 \\
\hline 9 & 6 & $\mathrm{~F}$ & $\mathrm{C}$ & 5 & $\sqrt{ }$ & 4 & 0.5 \\
\hline 10 & 17 & $\mathrm{M}$ & $\mathrm{C}$ & 4 & $\sqrt{ }$ & 2 & 0 \\
\hline 11 & 26 & $\mathrm{M}$ & $\mathrm{C}$ & 4 & $\sqrt{ }$ & 4 & 0.5 \\
\hline 12 & 30 & $\mathrm{~F}$ & $\mathrm{C}$ & 3 & $x$ & 2 & 0 \\
\hline 13 & 38 & $\mathrm{~F}$ & B & 2 & $x$ & 1.5 & 1 \\
\hline 14 & 38 & $\mathrm{M}$ & B & 3 & $\sqrt{ }$ & 4 & 2 \\
\hline 15 & 48 & $\mathrm{M}$ & $\mathrm{C}$ & 2 & $x$ & 3 & 0.5 \\
\hline 16 & 20 & $\mathrm{~F}$ & SM & 3 & $x$ & 4 & 1.5 \\
\hline 17 & 68 & $\mathrm{M}$ & B, SM & 3 & $x$ & 3 & 0.5 \\
\hline 18 & 36 & $\mathrm{M}$ & B & 3 & $\sqrt{ }$ & 4 & 0 \\
\hline 19 & 25 & $\mathrm{M}$ & $\mathrm{SM}$ & 4 & $\sqrt{ }$ & 3 & 1.5 \\
\hline 20 & 7 & $\mathrm{M}$ & $\mathrm{B}, \mathrm{C}$ & 4 & $x$ & 6 & 0 \\
\hline 21 & 34 & $\mathrm{M}$ & B & 2 & $\sqrt{ }$ & 5 & 0.5 \\
\hline 22 & 52 & $\mathrm{~F}$ & SL, SMen, SM & 4 & $x$ & 2 & 1.5 \\
\hline 23 & 18 & M & $\mathrm{C}$ & 3 & $x$ & 2 & -0.5 \\
\hline 24 & 37 & $\mathrm{~F}$ & SM,B & 3 & $\sqrt{ }$ & 2 & 0 \\
\hline 25 & 55 & M & $\mathrm{B}, \mathrm{C}$ & 4 & $x$ & 4 & 0.5 \\
\hline 26 & 24 & M & B & 3 & $x$ & 2 & 0.5 \\
\hline 27 & 53 & $\mathrm{M}$ & B, Smass & 7 & $\sqrt{ }$ & 4 & 1 \\
\hline 28 & 27 & M & SM & 3 & $x$ & 4 & 0.5 \\
\hline 29 & 37 & $\mathrm{M}$ & SL, SMen, SM & 4 & $x$ & 1 & 2 \\
\hline 30 & 37 & $\mathrm{~F}$ & SM & 4 & $x$ & 3 & 1 \\
\hline
\end{tabular}

LOS, length of stay; I \& D, incision and drainage; SM, submandibular; SMen, submental; SMass, submasseteric; SL, sublingual; B, buccal; C, canine. 


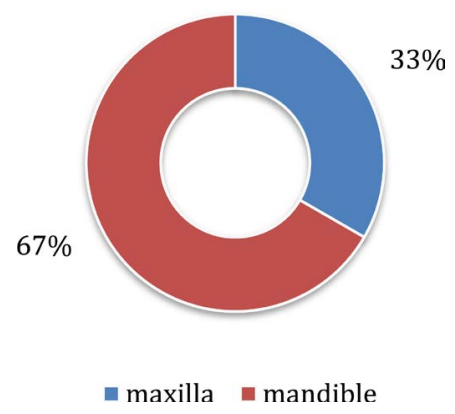

Figure 1. Site of involvement of MSI.

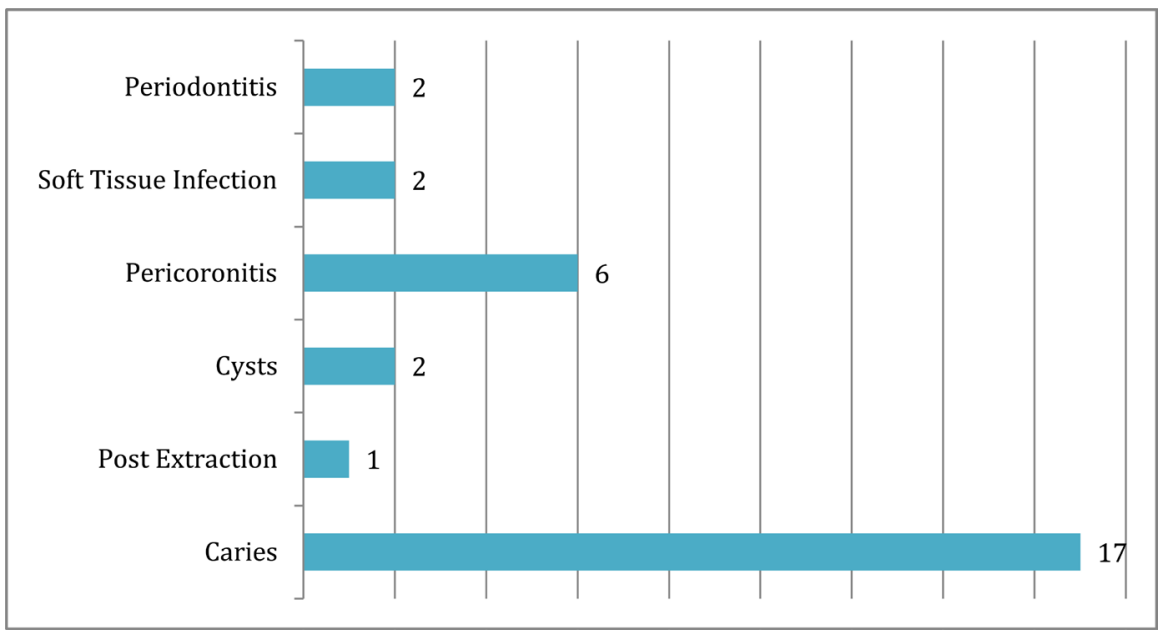

Figure 2. Distribution of patients according to identified source of MSI.

recorded as bilateral. $30 \%$ of patients presented with involvement of more than one anatomical space [Table 1].

Regarding the etiology of MSI, most frequent cause was dental caries (17 patients, representing $56 \%$ of recorded cases), followed by pericoronitis ( 6 patients, $20 \%)$, cysts, periodontitis and soft tissue injury ( 2 cases each, $6.6 \%$ each) and post extraction (1 patient, 3\%) [Figure 2].

Of the total study sample, incision and drainage under local anesthesia was done for $50 \%$ of the patients. The average length of stay in the hospital was 3.46 days. In terms of improvement in trismus ( 0 - 24 hours post steroid administration), a majority (33\%) of patients showed $0.5 \mathrm{~cm}$ increase in mouth opening, maximum improvement is of $2 \mathrm{~cm} \mathrm{(6.6 \% ).} \mathrm{However,} 13 \%$ of patients had reducing mouth opening and $20 \%$ showed no significant change [Figure 3]. $86 \%$ of patients showed a $2-4 \mathrm{~cm}$ reduction in swelling size $(0-24$ hours post steroid administration), whereas $6.6 \%$ showed improvement of more than $4 \mathrm{~cm}$ and less than $2 \mathrm{~cm}$ respectively [Figure 4].

\section{Discussion}

Traditionally, treatment of MSI involves prompt initiation of antibiotic therapy, with or without surgical intervention. Despite this, patients sometimes fail to improve, or even worse, deteriorate further. This is particularly observed in cases 


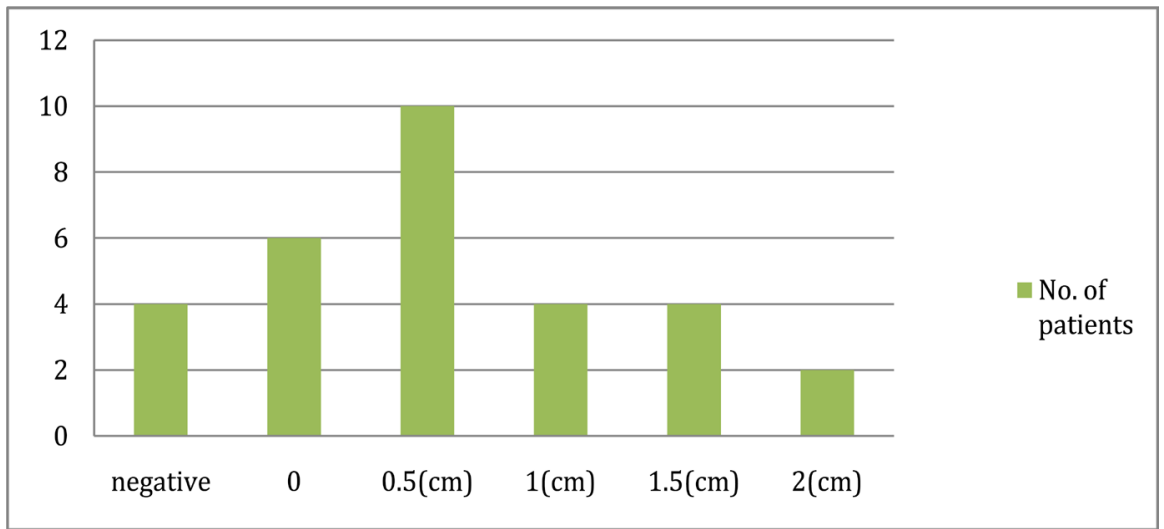

Figure 3. Changes in mouth opening post steroid administration.

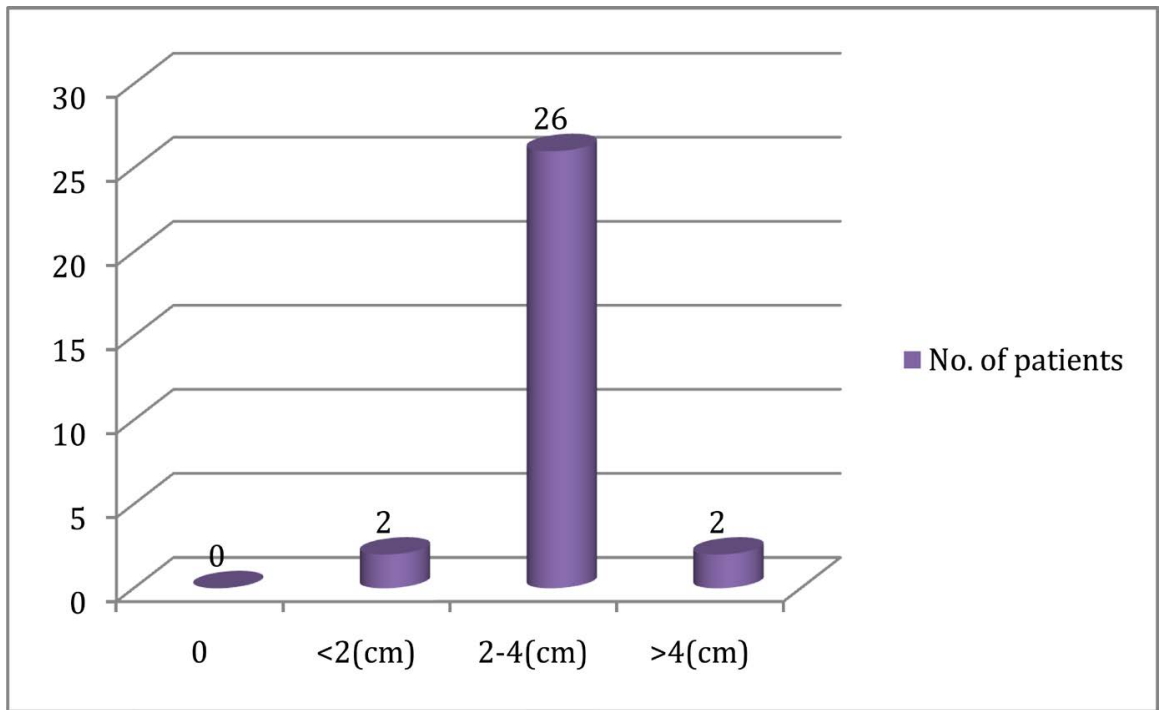

Figure 4. Changes in swelling size post steroid administration.

of Ludwig's angina. Delayed or lack of clinical improvement has been attributed by some authors, to a deficiency in host defence mechanism. The rationale of employing exogenous corticosteroids is to augment the body's natural defense response to combat infection in conjunction with antibiotic administration [29].

This unit treats an average of 100 to 120 MSI patients annually. Patients presenting with acute MSI with risk of rapid progression to Ludwig's angina or orbital cellulitis, were given adjunctive steroids (abiding exclusion criteria) along with broad-spectrum antibiotics. Significant clinical improvement was noted in the form of amelioration of pain, rapid reduction in edema (as shown in Figures 5-8), and improved trismus, shortening hospital stay to an average of 3 to 4 days, and omission of surgical intervention in $50 \%$ of our cases. In comparison, patients whom steroid administration was contraindicated have shown relatively slower clinical improvement and longer hospital stay (5 - 6 days). Case number $6,8,9$, and 25 showed reduction in mouth opening post Dexamethasone administration, this is likely attributable to post surgical edema following surgical removal of causative tooth. 


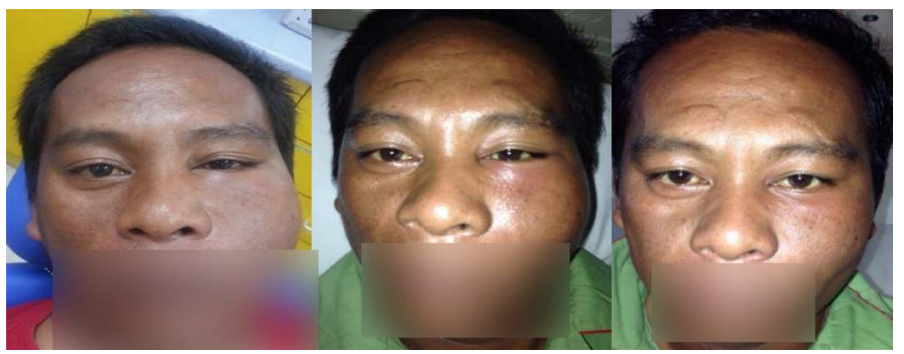

Figure 5. Case number 18; Day 1 to day 3 (from left to right).

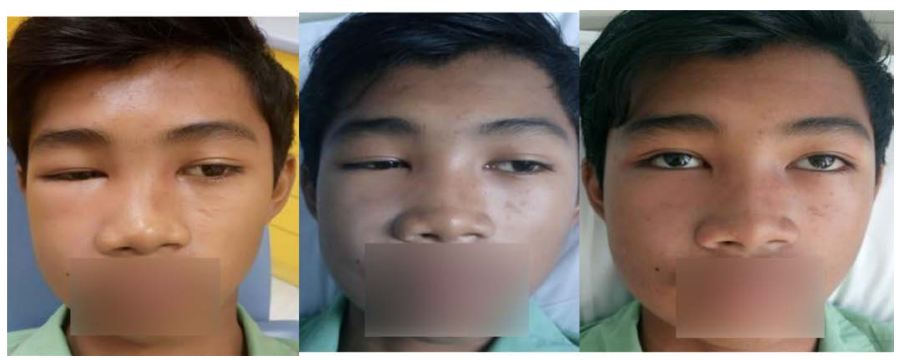

Figure 6. Case number 10; Day 1 to day 3 (from left to right).

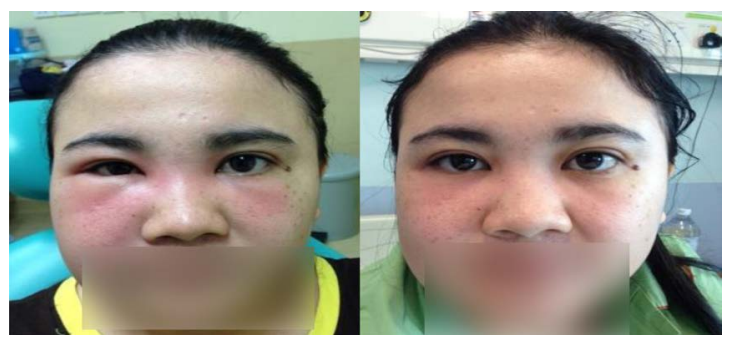

Figure 7. Case number 15; Day 1 to day 2 (from left to right).

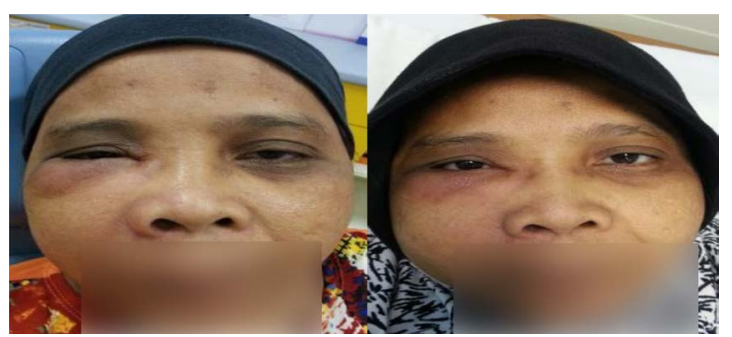

Figure 8. Case number 5; Day 1 to day 2 (from left to right).

These clinical parameters of disease improvement are markedly discernable following administration of one/two doses of Dexamethasone, attributable to the known anti-inflammatory and anti-edematous effects of corticosteroids. Corticosteroids inhibit transcription of pro-inflammatory mediators in human airway endothelial cells that cause pharyngeal inflammation and ultimately symptoms of pain [30] [31]. Lamkin and Portt (2006) reported that there was a striking degree of synergy between antibiotics and steroids in the treatment of various head and neck infections [32].

Some may argue that systemic corticosteroids could suppress body's natural immune response, potentially worsen the existing microbial infection sequelae. 
However, a regimen of short termed corticosteroids (3 doses at an interval of 8 hours) is unlikely to result in suppression of host immune response.

Many authors are advocating the use of systemic corticosteroids in the management of peritonsillar abscess and acute pharyngitis based on the promising findings from systemic review of relevant studies and clinical trials [30] [33] [34] [35] [36]. However, the role of corticosteroids in management of MSI has not been extensively studied [29] [37].

The ideal evidence to justify the conclusion that steroids improve the outcome in maxillofacial space infection management would be a study, which shows a clear comparison between 2 groups (group which receives intravenous antibiotics along with adjunctive steroids versus group which receives intravenous antibiotics without adjunctive steroids). However, as most retrospective studies, data of patients are often not complete. The comparison between steroids versus non-steroids group would be difficult and biased (Steroids are not given to diabetic patients in our centre, and comparing the 2 groups would further skew the results as most diabetic patients have poorer recovery). On the other hand, steroids are given as a first line adjunctive treatment in low-risk patients in this centre, hence the confounding factors of surgical intervention and antibiotics could not be negated.

\section{Conclusion}

In conclusion, the value of synergistic use of corticosteroids with antibiotics in management of MSI is significant. Despite these promising findings, there is scarce evidence in the literature to fully support the use of corticosteroids in MSI management. The role of corticosteroids in treatment of MSI should be explored further.

\section{Acknowledgements}

We are grateful to Datuk Dr. Noor Hisham Bin Abdullah, Dr. Hajah Kamariah Binti Ibrahim, Dr. Mahfudzah Binti Md Dean, and Dr. Azimah Binti A.Aziz for their support and permission to publish this paper.

\section{Conflict of Interest}

None declared.

\section{Consent}

Informed consent was obtained from the patients for publication and any accompanying images.

\section{References}

[1] Zhang, C., Tang, Y., Zheng, M., Yang, J., Zhu, G., Zhou, H., et al. (2010) Maxillofacial Space Infection Experience in West China: A Retrospective Study of 212 Cases. International Journal of Infectious Diseases, 14, e414-e417. https://doi.org/10.1016/j.ijid.2009.08.002 
[2] Topazian, R.G., Goldberg, M.H. and Hupp, J.R. (2002) Oral and Maxillofacial Infections. 4th Edition, WB Saunders Company, Philadelphia.

[3] Kim, M.K., Allareddy, V., Nalliah, R.P., et al. (2012) Burden of Facial Cellulitis: Estimates from the Nationwide Emergency Department Sample. Oral Surgery, Oral Medicine, Oral Pathology, Oral Radiology, 114, 312-317. https://doi.org/10.1016/j.tripleo.2011.07.043

[4] Jundt, J.S. and Gutta, R. (2012) Characteristics and Cost Impact of Severe Odontogenic Infections. Oral Surgery, Oral Medicine, Oral Pathology, Oral Radiology, 114, 558-566. https://doi.org/10.1016/j.oooo.2011.10.044

[5] Kim, M.K., Nalliah, R.P., Lee, M.K., et al. (2012) Factors Associated with Length of Stay and Hospital Charges for Patients Hospitalized with Mouth Cellulitis. Oral Surgery, Oral Medicine, Oral Pathology, Oral Radiology, 113, 21-28. https://doi.org/10.1016/j.tripleo.2011.01.012

[6] Hupp, J., Ellis III, E. and Tucker, M. (2008) Contemporary Oral and Maxillofacial Surgery. 5th Edition, Elsevier Health Sciences, St Louis, MO.

[7] Reynolds, S.C. and Chow, A.W. (2007) Life-Threatening Infections of the Peripharyngeal and Deep Fascial Spaces of the Head and Neck. Infectious Disease Clinics of North America, 21, 557-576. https://doi.org/10.1016/j.idc.2007.03.002

[8] Ryan, P. and McMahon, G. (2012) Severe Dental Infections in the Emergency Department. European Journal of Emergency Medicine, 19, 208-213.

https://doi.org/10.1097/MEJ.0b013e32834ddb68

[9] Zeitoun, I.M., et al. (1995) Cervical Cellulitis and Mediastinitis Caused by Odontogenic Infections. Journal of Oral and Maxillofacial Surgery, 53, 203-208. https://doi.org/10.1016/0278-2391(95)90404-2

[10] Bali, R.K., Sharma, P., Gaba, S., Kaur, A. and Ghanghas, P. (2015) A Review of Complications of Odontogenic Infections. National Journal of Maxillofacial Surgery, 6, 136-143. https://doi.org/10.4103/0975-5950.183867

[11] Filiaci, F., Riccardi, E., Mitro, V., et al. (2015) Disseminated Necrotic Mediastinitis Spread from Odontogenic Abscess: Our Experience. Annali di Stomatologia, 6, 64-68.

[12] Ryan, P. and McMahon, G. (2012) Severe Dental Infections in the Emergency Department. European Journal of Emergency Medicine, 19, 208-213. https://doi.org/10.1097/MEJ.0b013e32834ddb68

[13] Arias-Chamorro, B., Contreras-Morillo, M., Acosta-Moyano, A., Ruiz-Delgado, F., Bermudo-Añino, L. and Valiente-Álvarez, A. (2011) Multiple Odontogenic Abscesses. Thoracic and Abdomino-Perineal Extension in an Immuno Competent Patient. Medicina Oral Patologia Oral y Cirugia Bucal, 16, e772-e775. https://doi.org/10.4317/medoral.16852

[14] Amponsah, E. and Donkor, P. (2007) Life-Threatening Oro-Facial Infections. Ghana Medical Journal, 41, 33-36.

[15] Kim, M.S., Kim, S.G., Moon, S.Y., Oh, J.S., Park, J.U., Jeong, M.A., et al. (2011) Sepsis Developed from an Odontogenic Infection: Case Report. Journal of the Korean Association of Maxillofacial Plastic and Reconstructive Surgery, 33, 445-448.

[16] Levine, T.M., Wurster, C.F. and Krespi, Y.P. (1986) Mediastinitis Occurring as a Complication of Odontogenic Infections. Laryngoscope, 96, 747-750. https://doi.org/10.1288/00005537-198607000-00009

[17] Pappa, H. and Jones, D.C. (2005) Mediastinitis from Odontogenic Infection. A Case Report. British Dental Journal, 198, 547-548. https://doi.org/10.1038/sj.bdj.4812302 
[18] Fukuchi, M., Suzuki, O., Nasu, D., et al. (2015) Descending Necrotizing Mediastinitis Treated with Tooth Extractions Following Mediastinal and Cervical Drainage. Case Reports in Gastroenterology, 9, 311-316. https://doi.org/10.1159/000441386

[19] Akashi, M., Tanaka, K., Kusumoto, J., Furudoi, S., Hosoda, K., 2017Komori. Brain Abscess Potentially Resulting from Odontogenic Focus: Report of Three Cases and a Literature Review. Journal of Maxillofacial and Oral Surgery, 16, 58-64. https://doi.org/10.1007/s12663-016-0915-5

[20] Park, S.Y., Suh, D.W., Park, C.M., Oh, M.S. and Lee, D.-K. (2014) Brain Abscess Due to Odontogenic Infection: A Case Report. Journal of the Korean Association of Oral and Maxillofacial Surgeons, 40, 147-151. https://doi.org/10.5125/jkaoms.2014.40.3.147

[21] Basyuni, S., Sharma, V., Santhanam, V. and Ferro, A. (2015) Fatal Thalamic Abscess Secondary to Dental Infection. BMJ Case Reports, Published Online. https://doi.org/10.1136/bcr-2015-212589

[22] Greenstein, A., Witherspoon, R., Leinkram, D. and Malandreni, M. (2015) An Unusual Case of a Brain Abscess Arising from an Odontogenic Infection. Australian Dental Journal, 60, 532-535. https://doi.org/10.1111/adj.12266

[23] Verma, R., Junewar, V., Singh, R.K., Ram, H. and Pal, U.S. (2013) Bilateral Cavernous Sinus Thrombosis and Facial Palsy as Complications of Dental Abscess. National Journal of Maxillofacial Surgery, 4, 252-255. https://doi.org/10.4103/0975-5950.127664

[24] Yeo, G.-S., Kim, H.Y., Kwak, E.-J., Jung, Y.-S., Park, H.-S. and Jung, H.-D. (2014) Cavernous Sinus Thrombosis Caused by a Dental Infection: A Case Report. Journal of the Korean Association of Oral and Maxillofacial Surgeons, 40, 195-198. https://doi.org/10.5125/jkaoms.2014.40.4.195

[25] Cariati, P., Cabello-Serrano, A., Monsalve-Iglesias, F., Roman-Ramos, M. and Garcia-Medina, B. (2016) Meningitis and Subdural Empyema as Complication of Pterygomandibular Space Abscess upon Tooth Extraction. Journal of Clinical and EXperimental Dentistry, 8, e469-e472.

[26] Arias-Chamorro, B., Contreras-Morillo, M., Acosta-Moyano, A., Ruiz-Delgado, F., Bermudo-Añino, L. and Valiente-Álvarez, A. (2011) Multiple Odontogenic Abscesses. Thoracic and Abdomino-Perineal Extension in an Immuno Competent Patient. Medicina Oral Patologia Oral y Cirugia Bucal, 16, e772-e775. https://doi.org/10.4317/medoral.16852

[27] Britt, J.C., Josephson, G.D. and Gross, C.W. (2000) Ludwig's Angina in the Pediatric Population: Report of a Case and Review of the Literature. International Journal of Pediatric Otorhinolaryngology, 52, 79-87. https://doi.org/10.1016/S0165-5876(99)00295-5

[28] Galioto, N.J. (2008) Peritonsillar Abscess. American Family Physician, 77, 199-202.

[29] Hutchison, I.L. and James, D.R. (1989) Letters to the Editor. New Treatment for Ludwig's Angina. British Journal of Oral and Maxillofacial Surgery, 27, 83-84. https://doi.org/10.1016/0266-4356(89)90135-6

[30] Hayward, G., Thompson, M., Heneghan, C., Perera, R., Del Mar, C. and Glasziou, P. (2009) Corticosteroids for Pain Relief in Sore Throat: Systemic Review and Meta-Analysis. BMJ, 339, b2976. https://doi.org/10.1136/bmj.b2976

[31] Van Cauwenberge, P., Van Hoecke, H., Vandenbulcke, L., Van Zele, T. and Bachert, C. (2005) Glucocorticosteroids in Allergic Inflammation: Clinical Benefits in Allergic Rhinitis, Rhinosinusitis, and Otitis Media. Immunology and Allergy Clinics of North America, 25, 489-509. https://doi.org/10.1016/j.iac.2005.05.001 
[32] Lamkin, R.H. and Portt, J. (2006) An Outpatient Medical Treatment Protocol for Peritonsillar Abscess. Ear, Nose \& Throat Journal, 85, 658, 660.

[33] Chau, J.K.M., Seikaly, H.R., Harris, J.R., Villa-Roel, C., Brick, C. and Rowe, B.H. (2014) Corticosteroids in Peritonsillar Abscess Treatment: A Blinded Placebo-Controlled Clinical Trial. Laryngoscope, 124, 97-103. https://doi.org/10.1002/lary.24283

[34] Lee, Y.J., Jeong, Y.M., Lee, H.S. and Hwang, S.H. (2016) The Efficacy of Corticosteroids in the Treatment of Peritonsillar Abscess: A Meta-Analysis. Clinical and EXperimental Otorhinolaryngology, 9, 89-97. https://doi.org/10.21053/ceo.2014.01851

[35] Korb, K., Scherer, M. and Chenot, J.F. (2010) Steroids as Adjuvant Therapy for Acute Pharyngitis in Ambulatory Patients: A Systematic Review. The Annals of Family Medicine, 8, 58-63. https://doi.org/10.1370/afm.1038

[36] Kiderman, A., Yaphe, J., Bregman, J., Zemel, T. and Furst, A.L. (2005) Adjuvant Prednisone Therapy in Pharyngitis: A Randomised Controlled Trial from General Practice. British Journal of General Practice, 55, 218-221.

[37] Freund, B. and Timon, C. (1992) Ludwig's Angina: A Place for Steroid Therapy in Its Management? Oral Health, 82, 23-25.

\section{Scientific Research Publishing}

\section{Submit or recommend next manuscript to SCIRP and we will provide best} service for you:

Accepting pre-submission inquiries through Email, Facebook, LinkedIn, Twitter, etc. A wide selection of journals (inclusive of 9 subjects, more than 200 journals) Providing 24-hour high-quality service User-friendly online submission system Fair and swift peer-review system Efficient typesetting and proofreading procedure Display of the result of downloads and visits, as well as the number of cited articles Maximum dissemination of your research work

Submit your manuscript at: http://papersubmission.scirp.org/ Or contact ojst@scirp.org 